${ }^{1}$ Department of Vascular and Internal Diseases, Jan Biziel University Hospital No. 2 in Bydgoszcz, Bydgoszcz, Poland

2Department of Vascular and Internal Diseases, Faculty of Health Sciences, Ludwik Rydygier Collegium Medicum in Bydgoszcz, Nicolaus Copernicus University in Torun, Poland

\title{
Relation between parameters of body composition and echocardiography in patients with nonvalvular atrial fibrillation
}

\section{Corresponding author:}

Jacek Budzyński, Department of Vascular and Internal Diseases, Jan Biziel University Hospital No. 2 in Bydgoszcz, 75 Ujejskiego Street, 85-168 Bydgoszcz, Poland, e-mail: budz@cps.pl
Medical Research Journal 2020; Volume 5, Number 3, 167-176 10.5603/MRJ.a2020.0033 Copyright ( 2020 Via Medica ISSN 2451-2591

\begin{abstract}
Purpose: Both nutritional status and echocardiographic parameters are associated with the risk of atrial fibrillation (AF). The aim of this study was to determine the relationships between parameters of transthoracic echocardiography and nutritional status assessment as risk factors for $\mathrm{AF}$.

Methods: This cross-sectional study considered 120 consecutive patients hospitalized due to AF and 240 inpatients admitted due to exacerbation of cardiovascular conditions. Echocardiographic parameters and parameters of nutritional status were determined for each patient.

Results: Patients in the lowest body mass index (BMI) quartile and without visceral adiposity had the lowest standard echocardiographic parameters; however, the majority of these differences disappeared after the parameters were indexed to BSA. In logistic regression analysis, echocardiographic parameters were associated with slightly higher or similar AF risk comparing with parameters of nutritional status assessment. When the comparison was made in relation to cut-off values obtained in ROC analysis, then having a visceral adipose tissue (VAT) score $\geq 12$ was associated with a lower increase in AF risk (odds ratio $[\mathrm{OR}]$; $95 \%$ confidence interval $[\mathrm{Cl}]: 3.09 ; 1.85-5.15)$ than the risk increase associated with e.g. left atrium diameter greater than $45 \mathrm{~mm}$ ([OR; 95\% Cl] 10.483; 6.308-17.421).

Conclusions: The unitary values of echocardiographic and body composition parameters only slightly differed in relation to the risk of AF occurrence, however, the use of cut-off values significantly increases an impact of echocardiography on the prediction of AF. The U-shaped relationships between a patient's nutritional status and AF occurrence cannot be explained by the effect of body mass on cardiac structure and size.
\end{abstract}

Key words: atrial fibrillation, body composition, echocardiography, visceral adiposity

Med Res J 2020; 5 (3): 167-176

\section{Introduction}

Disturbances in nutritional status and atrial fibrillation (AF) are significant current health problems. Obesity is one of the evidenced risk factors for AF [1, 2], although diabetes mellitus, hypertension, obstructive sleep apnea, enlargement of the left atrium, and cardiac failure also influence the risk of atrial arrhythmia [3, 4]. However, the importance of undernutrition as a risk factor for $\mathrm{AF}$ is understudied due to the exclusion of patients with a body mass index (BMI) $<18.5 \mathrm{~kg} / \mathrm{m}^{2}$ from the majority of studies on associations between patients' nutritional status and the risk of various cardiovascular conditions [1].

Echocardiography is a basic diagnostic tool for patients with cardiovascular disorders. In patients with $\mathrm{AF}$, the tool helps to identify the cause of arrhythmia (e.g. valvular AF, nonvalvular AF, cardiomyopathy), to localize the site of arrhythmia complication (e.g. the presence of thrombus in the left atrial appendage), to predict the risk of arrhythmia recurrence (e.g. left atrium diameter), and to treat patients with arrhythmia (e.g. during left atrium appendage closure) [5]. It seems reasonable that individuals with greater height and body 
size have higher echocardiographic parameter values than people who are smaller [6]. However, reductions in body mass and changes in body composition after bariatric surgery (unrelated to changes in patients' height) led to a reduction in values of echocardiographic parameters of the left ventricle [7-9]. Moreover, the associations between heart dimensions and nutritional status are complicated by the distribution of adiposity, which an example is the relationship between epicardial adipose tissue (EAT) and left atrial size that was found to be positive for patients with paroxysmal AF and negative for patients with permanent AF [10]. Such effect of fat tissue on heart remodelling and risk of arrhythmia is explained by its paracrine, endocrine and proinflammatory properties [10-12]. These data suggest that the association between heart morphology and function and patient nutritional status may be more complicated than simply a relationship with body size or body surface area (BSA). As a result of left ventricle enlargement, hypertrophy, diastolic and systolic dysfunction, as well as an increase in left atrial diameter, area and volume is associated with a rise in patient morbidity and mortality [13], and risk of AF occurrence and recurrence after cardioversion [5], we tried to answer the following questions: (a) Are there any relationships between the parameters of transthoracic echocardiography and nutritional status assessment (e.g. BMI)? (b) Are there any relationships between the parameters of transthoracic echocardiography and adiposity distribution? and (c) What is the strength of the relationship between the parameters of echocardiography and nutritional status assessment and the risk of AF occurrence?

\section{Materials and methods}

\section{Patients}

This cross-sectional study considered 120 consecutive patients hospitalized due to nonvalvular AF and 240 inpatients admitted to hospital due to exacerbation of cardiovascular conditions (control group). The exclusion criteria were: history or clinical signs of inflammatory processes or neoplasm or valvular heart disease; a significant decrease in body weight during the three months prior to the current hospitalization (i.e. a quotient of [ $100 \% \times$ (usual weight - actual weight)/ /usual body weight] being greater than $5 \%$ ); the history of disorders affecting food intake or absorption; lack of informed consent for participation in the study; and an implanted cardioverter or cardiostimulator (a contraindication for bioelectrical impedance analysis, BIA). Patients were recruited to the study between July 01, 2015, and December 31, 2016.
During the first day of hospitalization, a medical history was obtained from each of the inpatients enrolled in the study and a physical examination was performed, including the measurement of anthropometric parameters of nutritional status. An electrocardiogram (ECG) and transthoracic echocardiography were also performed for each patient.

\section{Biochemical determinations}

Blood samples for routine determinations, including $\mathrm{NH}(2)$-terminal pro-brain natriuretic peptide (NT-proBNP) were taken from the ulnar vein of each patient between 7 am and 8 am on the day of admission while the patients were in a fasting state.

\section{Parameters of nutritional status assessment}

A nutritional status assessment was performed for all the study participants. The following parameters were measured: height $(\mathrm{cm})$, body weight $(\mathrm{kg})$, waist circumference (WC, cm), hip circumference $(\mathrm{HC}, \mathrm{cm})$, mid-arm circumference (MAC, $\mathrm{cm}$ ), as well as the handgrip strength of the predominant hand. All circumferences were measured using tape, skinfolds with a Harpenden MG-4800 skinfold manual caliper (produced by BATY, UK), and handgrip strength using an electronic dynamometer (manufactured by Kern, Germany). Body composition was determined using BIA and a TANITA BC 420 MA device (TANITA Corporation, Japan). The following BIA parameters were analyzed: fat mass (FM; \% and kg), visceral adipose tissue (VAT) level (in the range 1-59, a level > 26 showing abdominal adiposity), fat-free mass (FFM, kg), predicted muscle mass (PMM, kg), which assesses both smooth and skeletal muscle mass, skeletal muscle mass (SMM, expressed in \%, kg), bone mass (BM, kg), total body water (TBW; and kg), basal metabolic rate (BMR, kcal), and metabolic age (MA, years).

The following secondary parameters were calculated based on the above-mentioned indices:

- BMl $(\mathrm{kg} / \mathrm{m} 2)$ - calculated as a quotient of body mass expressed in $\mathrm{kg}$ and squared height expressed in $\mathrm{m}$;

- an "ideal weight" - calculated according to the Lorentz formula: for female patients, ideal weight $=$ [height $(\mathrm{cm})-100]-\{$ height $(\mathrm{cm})-150] / 2\}$; and for male patients, ideal weight $=$ height $(\mathrm{cm})$ $-100]-\{$ [height $(\mathrm{cm})-150] / 4\}$;

- the quotient of actual (current) to ideal body mass $\times 100 \%$; "body mass deficit" was diagnosed when this quotient value was below $100 \%$;

- waist-to-hip ratio (WHR) - calculated as the quotient of WC and HC; the cut-off values for diagnosis of abdominal adiposity were 0.8 for females and 1.0 for males; 
- waist-to-height ratio $(\mathrm{WHtR})$ - calculated as the quotient of WC to height $(\mathrm{cm}) \times 100$; the established cut-off values of this index for diagnosis of abdominal adiposity (the central or android type of obesity) were 0.58 for females and 0.63 for males [14-16],

- skeletal muscle mass index (SMI) - calculated as a quotient of skeletal muscle mass obtained in BIA expressed in $\mathrm{kg}$ and squared height expressed in $\mathrm{m}$.

\section{Parameters of transthoracic echocardiography}

Echocardiography was performed at admission by the same, experienced cardiologist, using a transthoracic ultrasound device (Aplio, TOSHIBA) and a $10 \mathrm{MHz}$ radial probe. The following echocardiographic parameters concerning both left ventricle (LV) and left atrium (LA) were determined: interventricular septum thickness (IVST, mm) at end-diastole; posterior wall thickness (PWT, mm) at end-diastole; left ventricular end-diastolic dimension (LVEDD, mm); mean wall thickness (MWT, $\mathrm{mm}$ ); relative wall thickness (RWT, $\mathrm{mm}$ ); left ventricular mass (LVM, g); left ventricular mass indexed to body surface area (LVM/BSA, $\mathrm{g} / \mathrm{m}^{2}$ ); left ventricular ejection fraction (LVEF, \%); left atrium diameter (LAD, mm); left atrium diameter indexed to body surface area (LAD/BSA, $\mathrm{mm} / \mathrm{m}^{2}$ ); left atrium area (LAA, $\left.\mathrm{cm}^{2}\right)$ in apical four- and two-chamber views (LAA4 and LAA2); left atrium area in apical four- and two-chamber views indexed to body surface area (LAA4/BSA, LAA2/BSA, $\mathrm{cm}^{2} / \mathrm{m}^{2}$ ); left atrium volume in apical four- and two-chamber views (LAV4 and LAV2, $\mathrm{ml}$ ); and left atrium volume in apical four- and two-chamber views indexed to body surface area (LAV4/BSA and LAV2/BSA, $\mathrm{ml} / \mathrm{m}^{2}$ ). A left atrial volume was assessed using the biplane method. Left ventricular mass was calculated using the following formula:

$$
\begin{aligned}
\operatorname{LVM}(\mathrm{g})=0.8 \times & \left\{1.04 \times\left([\mathrm{LVEDD}+\mathrm{IVST}+\mathrm{PWT}]^{3}\right.\right. \\
& \left.\left.-\operatorname{LVEDD}^{3}\right)\right\}+0.6
\end{aligned}
$$

Body surface area was calculated using the following formula:

$$
\text { BSA }\left(m^{2}\right)=0,01666667 \times \text { height }^{0.5} \times \text { body mass } \text { b. }^{0.5}
$$

\section{Bioethics}

The investigation was conducted in compliance with the Declaration of Helsinki for medical research, after receiving permission from local Bioethical Committee No. 389/2015. Each patient gave written consent to participate in the study.

\section{Statistics}

Statistical analysis was conducted using a licensed version of statistical software STATISTICA version 13.1 (a data analysis software system) developed by
StatSoft, Inc. (2017). The statistical significance level was set at a $p$-value $<0.05$. The normal distribution of the study variables was checked using the Shapiro-Wilk test. The results were mainly presented as the mean \pm standard deviation, or $n, \%$. The statistical significance of differences between groups was verified using the Student's t-test, the Mann-Whitney U test and the $\mathrm{Chi}^{2}$ test. Logistic regression analysis with a quasi-Newton estimation model was used to determine the odds ratio (OR) and 95\% confidence interval $(\mathrm{Cl})$ of the one unit of the continuous (quantity) variables in relation to the risk of atrial fibrillation occurrence. Cut-off values for respective parameters of echocardiography and parameters of nutritional status assessment that have a predictive value for the risk of the atrial fibrillation were determined for maximal Youden indices by plotting the receiver operator curves (ROC). All the patients were then classified into two groups based on those cut-off values. For such obtained qualitative variables, using free internet calculator (https://www.medcalc.org/calc/ odds_ratio.php), the OR was determined as the risk that atrial fibrillation would occur with an associated higher value of a respective variable (e.g. $L A D \geq 45 \mathrm{~mm}$ or LVED $\geq 48 \mathrm{~mm}$ ), compared to the chance of the atrial fibrillation occurring in patients with its lower value (e.g. LAD $<45 \mathrm{~mm}$ or LVED $<48 \mathrm{~mm}$ ).

\section{Results}

\section{Clinical characteristics}

While individuals with a BMI value in the lowest quartile were similar to patients from the higher quartiles in relation to the clinical variables, the lowest quartile group had significantly lower values for the majority of the estimated crude echocardiographic parameters (Tab. 1). However, when echocardiographic parameters were indexed to body surface area, these significant differences either disappeared or were less apparent. After adjustment for BSA, the only statistically significant difference between the patient groups divided in relation to $\mathrm{BMI}$ quartiles concerned the left atrium diameter, which was higher in patients from the lowest BMI quartile compared to the other patient groups (Tab. 1).

\section{Associations between parameters of abdominal adiposity and echocardiography}

Next, we compared the values of the echocardiographic parameters in a split analysis performed in relation to generally accepted cut-off criteria for WHR (data not presented in detail) and WHtR (Tab. 2) for abdominal adiposity, as well as in relation to the median VAT score in BIA, which was 12 (data not presented in 
Table 1. Clinical and echocardiographic parameters in relation to quartiles of BMI

\begin{tabular}{|c|c|c|c|c|}
\hline Parameter & $\begin{aligned} \mathrm{BMI} & <24.42 \\
(\mathrm{n} & =90)\end{aligned}$ & $\begin{array}{c}24.42 \leq \text { BMI } \\
<27.66 \\
(n=90)\end{array}$ & $\begin{array}{c}27.66 \leq \mathrm{BMI} \\
<31.59 \\
(\mathrm{n}=90)\end{array}$ & $\begin{aligned} \mathrm{BMI} & \geq 31.59 \\
(\mathrm{n} & =90)\end{aligned}$ \\
\hline Age (years) & $72.20 \pm 9.37$ & $70.43 \pm 9.10$ & $68.55 \pm 8.99$ & $69.10 \pm 8.98$ \\
\hline Male gender (n, \%) & $40(44.44 \%)$ & $42(46.67 \%)$ & 58 (64.44\%) & 39 (43.33\%) \# \\
\hline $\begin{array}{l}\text { Smoking habit }(n, \%) \text {, currently/in the } \\
\text { past }\end{array}$ & $\begin{array}{l}27(30.00 \%) \\
34(37.78 \%)\end{array}$ & $\begin{array}{l}25(27.78 \%) \\
31(34.44 \%)\end{array}$ & $\begin{array}{l}22(24.44 \%) \\
40(44.44 \%)\end{array}$ & $\begin{array}{l}10(11.11 \%) \\
44(48.89 \%)\end{array}$ \\
\hline Hypertension (n, \%) & $65(72.22 \%)$ & $84(93.33 \%)^{*}$ & $78(86.67 \%)$ & $83(92.22 \%)^{*}$ \\
\hline Diabetes mellitus (n, \%) & $22(24.44 \%)$ & $35(38.89 \%)$ * & $40(44.44 \%)^{\star}$ & $44(48.89 \%)^{*}$ \\
\hline Past myocardial infarction (n, \%) & $11(12.22 \%)$ & $19(21.11 \%)$ & $16(17.78 \%)$ & $20(22.22 \%)$ \\
\hline CABG (n, \%) & $5(5.56 \%)$ & $7(7.78 \%)$ & $6(6.67 \%)$ & $12(13.33 \%)$ \\
\hline $\mathrm{PCl}(\mathrm{n}, \%)$ & $16(17.78 \%)$ & $15(16.67 \%)$ & $11(12.22 \%)$ & $15(16.67 \%)$ \\
\hline Atrial fibrillation (n, \%) & 20 (22.22\%) & 25 (27.78\%) & $32(35.56 \%)$ & $45(50 \%) * \#$ \\
\hline NYHA class (III-IV, n, \%) & $10(11.11 \%)$ & $6(6.67 \%)$ & 7 (7.78\%) & $23(25.56 \%) *+\#$ \\
\hline NT-proBNP (pg/ml) & $1800.84 \pm 3254.82$ & $972.79 \pm 3254.82^{*}$ & $846.72 \pm 1362.90 *$ & $1542.17 \pm 2426.32 \#$ \\
\hline $\begin{array}{l}\text { Interventricular septum thickness } \\
\text { at end-diastole (mm) }\end{array}$ & $10.53 \pm 1.69$ & $11.06 \pm 1.86^{*}$ & $11.79 \pm 1.64^{\star}+$ & $12.5 \pm 1.84^{*}+\#$ \\
\hline $\begin{array}{l}\text { Posterior wall thickness at end-diastole } \\
(\mathrm{mm})\end{array}$ & $10.18 \pm 1.88$ & $10.64 \pm 1.84$ & $11.33 \pm 1.64^{\star}+$ & $12.0 \pm 1.56^{*}+\#$ \\
\hline $\begin{array}{l}\text { Left ventricular end-diastolic dimension } \\
(\mathrm{mm})\end{array}$ & $47.02 \pm 6.10$ & $47.41 \pm 8.71$ & $49.24 \pm 8.79$ & $49.8 \pm 8.26^{*}$ \\
\hline Mean wall thickness (mm) & $10.35 \pm 1.74$ & $10.85 \pm 1.81$ & $11.56 \pm 1.59 *+$ & $12.2 \pm 1.62^{\star}+\#$ \\
\hline Relative wall thickness (mm) & $0.45 \pm 0.09$ & $0.54 \pm 0.58$ & $0.57 \pm 0.73$ & $0.5 \pm 0.40^{*}$ \\
\hline Left ventricular mass (g) & $180.91 \pm 59.65$ & $197.18 \pm 74.45$ & $227.35 \pm 70.90 *+$ & $249.30 \pm 72.50 *+\#$ \\
\hline $\begin{array}{l}\text { Left ventricular mass indexed to BSA ( } g / \\
\mathrm{m}^{2} \text { ) }\end{array}$ & $109.07 \pm 33.33$ & $107.22 \pm 36.45$ & $113.67 \pm 32.59$ & $117.42 \pm 31.19+$ \\
\hline Left ventricular ejection fraction (\%) & $58.34 \pm 11.98$ & $57.66 \pm 10.19$ & $57.15 \pm 10.76$ & $55.2 \pm 10.83$ \\
\hline Left atrium diameter (mm) & $39.11 \pm 7.11$ & $41.09 \pm 5.44^{*}$ & $43.27 \pm 6.77^{\star}+$ & $46.1 \pm 7.20^{\star}+\#$ \\
\hline $\begin{array}{l}\text { Left atrium diameter indexed to BSA } \\
\left(\mathrm{mm} / \mathrm{m}^{2}\right)\end{array}$ & $23.78 \pm 4.56$ & $22.57 \pm 3.05^{\star}$ & $21.78 \pm 3.48^{\star}$ & $21.9 \pm 3.74^{*}$ \\
\hline $\begin{array}{l}\text { Left atrium area in apical four-chamber } \\
\text { view }\left(\mathrm{cm}^{2}\right)\end{array}$ & $19.86 \pm 6.23$ & $20.41 \pm 5.26$ & $23.83 \pm 10.58^{\star}+$ & $27.50 \pm 17.66^{*}+$ \\
\hline $\begin{array}{l}\text { Left atrium area in apical two-chamber view } \\
\left(\mathrm{cm}^{2}\right)\end{array}$ & $21.41 \pm 5.21$ & $21.91 \pm 5.63$ & $23.29 \pm 5.58^{*}$ & $26.30 \pm 5.31+\#$ \\
\hline $\begin{array}{l}\text { Left atrium area in apical four-chamber } \\
\text { view indexed to } B S A\left(\mathrm{~cm}^{2} / \mathrm{m}^{2}\right)\end{array}$ & $12.07 \pm 3.79$ & $11.18 \pm 2.77$ & $11.95 \pm 4.97$ & $13.0 \pm 7.90+$ \\
\hline $\begin{array}{l}\text { Left atrium area in apical two-chamber view } \\
\text { indexed to } \mathrm{BSA}\left(\mathrm{cm}^{2} / \mathrm{m}^{2}\right)\end{array}$ & $13.01 \pm 3.91$ & $12.01 \pm 3.01$ & $11.72 \pm 2.76^{\star}$ & $12.50 \pm 2.79$ \\
\hline $\begin{array}{l}\text { Left atrium volume in apical four-chamber } \\
\text { view (ml) }\end{array}$ & $71.31 \pm 36.28$ & $73.00 \pm 29.58$ & $84.48 \pm 28.15^{\star}+$ & $99.7 \pm 30.32^{*}+\#$ \\
\hline $\begin{array}{l}\text { Left atrium volume in apical two-chamber } \\
\text { view }(\mathrm{ml})\end{array}$ & $74.43 \pm 36.16$ & $77.43 \pm 31.86$ & $86.89 \pm 30.46^{\star}+$ & $102.6 \pm 30.43^{*}+\#$ \\
\hline $\begin{array}{l}\text { Left atrium volume in apical four-chamber } \\
\text { view indexed to BSA }\left(\mathrm{ml} / \mathrm{m}^{2}\right)\end{array}$ & $43.21 \pm 21.51$ & $39.85 \pm 15.36$ & $42.46 \pm 14.30$ & $47.2 \pm 14.37+\#$ \\
\hline $\begin{array}{l}\text { Left atrium volume in apical two-chamber } \\
\text { view indexed to BSA }\left(\mathrm{ml} / \mathrm{m}^{2}\right)\end{array}$ & $45.15 \pm 21.82$ & $42.31 \pm 16.74$ & $43.58 \pm 15.07$ & $48.7 \pm 15.15+\#$ \\
\hline
\end{tabular}

$\mathrm{AF}$ - atrial fibrillation; BMI — body mass index; BSA — body surface area; CABG — coronary artery bypass graft; NT-proBNP — NH(2)-terminal pro-brain natriuretic peptide; NYHA — the stage of heart failure according to the New York Heart Association classification; PCl - percutaneous coronary intervention. Statistical significance of difference: ${ }^{\star} p<0.05$ between columns 1 and $2,3,4 ;+=p<0.05$ between columns 2 and 3 , 4 ; $\# \mathrm{p}<0.05$ between columns 3 and 4 
Table 2. Echocardiographic parameters in patients in relation to type of adiposity diagnosed in relation to standard gender-related cut-off values of WHtR

\begin{tabular}{|c|c|c|c|}
\hline Parameter & $\begin{array}{c}\text { WHtR } \geq 0.58 / 0.63 \\
(n=200)\end{array}$ & $\begin{array}{c}\text { WHtR }<0.58 / 0.63 \\
(n=160)\end{array}$ & $\mathbf{p}$ \\
\hline Interventricular septum thickness at end-diastole (mm) & $11.83 \pm 1.94$ & $10.99 \pm 1.74$ & $<0.001$ \\
\hline Posterior wall thickness at end-diastole (mm) & $11.41 \pm 1.79$ & $10.57 \pm 1.85$ & $<0.001$ \\
\hline Left ventricular end-diastolic dimension (mm) & $48.82 \pm 7.70$ & $47.81 \pm 8.54$ & 0.240 \\
\hline Mean wall thickness (mm) & $11.62 \pm 1.80$ & $10.78 \pm 1.76$ & $<0.001$ \\
\hline Relative wall thickness (mm) & $0.52 \pm 0.41$ & $0.53 \pm 0.61$ & 0.86 \\
\hline Left ventricular mass $(\mathrm{g})$ & $225.47 \pm 72.28$ & $199.09 \pm 74.33$ & $<0.001$ \\
\hline Left ventricular mass indexed to BSA $\left(\mathrm{g} / \mathrm{m}^{2}\right)$ & $114.88 \pm 32.43$ & $108.05 \pm 34.63$ & 0.055 \\
\hline Left ventricular ejection fraction (\%) & $56.04 \pm 11.10$ & $58.40 \pm 10.67$ & 0.043 \\
\hline Left atrium diameter $(\mathrm{mm})$ & $43.66 \pm 7.29$ & $40.74 \pm 6.62$ & $<0.001$ \\
\hline Left atrium diameter indexed to $B S A\left(\mathrm{~mm} / \mathrm{m}^{2}\right)$ & $22.51 \pm 3.80$ & $22.46 \pm 3.86$ & 0.914 \\
\hline Left atrium area in apical four-chamber view $\left(\mathrm{cm}^{2}\right)$ & $24.67 \pm 14.21$ & $20.65 \pm 5.77$ & $<0.001$ \\
\hline Left atrium area in apical two-chamber view $\left(\mathrm{cm}^{2}\right)$ & $24.16 \pm 5.82$ & $22.09 \pm 6.08$ & 0.0012 \\
\hline Left atrium area in apical four-chamber view indexed to $\mathrm{BSA}\left(\mathrm{cm}^{2} / \mathrm{m}^{2}\right)$ & $12.58 \pm 6.38$ & $11.36 \pm 3.19$ & 0.028 \\
\hline Left atrium area in apical two-chamber view indexed to $\mathrm{BSA}\left(\mathrm{cm}^{2} / \mathrm{m}^{2}\right)$ & $12.35 \pm 3.03$ & $12.18 \pm 3.49$ & 0.627 \\
\hline Left atrium volume in apical four-chamber view (ml) & $88.07 \pm 32.01$ & $74.57 \pm 33.02$ & $<0.001$ \\
\hline Left atrium volume in apical two-chamber view (ml) & $91.11 \pm 32.31$ & $78.23 \pm 34.79$ & $<0.001$ \\
\hline Left atrium volume in apical four-chamber view indexed to BSA $\left(\mathrm{ml} / \mathrm{m}^{2}\right)$ & $44.97 \pm 15.54$ & $40.87 \pm 18.01$ & 0.021 \\
\hline Left atrium volume in apical two-chamber view indexed to BSA $\left(\mathrm{ml} / \mathrm{m}^{2}\right)$ & $46.31 \pm 16.14$ & $42.67 \pm 19.46$ & 0.053 \\
\hline
\end{tabular}

BSA — body surface area; WHtR - waist-to-height ratio, with 0.58 as the cut-off value for abdominal adiposity in women and 0.63 as the cut-off value for men

detail). We found that patients with abdominal adiposity had significantly greater values for the majority of crude echocardiographic parameters analyzed, with the exception of LVEF, which was significantly lower. However, after indexing the echocardiographic parameters by BSA, the only statistically significant differences [in the split analysis] concerned LAA4 and LAV4 in relation to $\mathrm{WHtR}$ value and LAD and LAV4 in relation to VAT score. On the other hand, patients with a body weight deficit ( $n=33 ; 9.17 \%$ ) had lower values for the echocardiographic parameters analyzed, and the statistical significance of these differences disappeared after indexing to BSA (data not presented in detail). However, patients with body weight deficit had significantly higher blood NT-proBNP concentration than their counterparts $(2707.09 \pm 4458.03$ vs. $1143.50 \pm 2044.90 \mathrm{pg} / \mathrm{ml}$; $\mathrm{p}<0.001)$.

\section{Spearman's correlation between} echocardiographic parameters and BIA

In order to determine the strength of the relationships between the parameters of nutritional status assessment and the echocardiographic indices, we also performed a regression analysis using Spear- man's correlations (Tab. 3). The strongest relationships concerned such crude echocardiographic parameters as LVM, LVEDD, LAD, LAA, LAV, IVST, and PWT. The relationships showed that BIA parameters of nutritional status assessment (body composition) explained $2-27 \%$ of the variance in echocardiographic parameters. However, the power of these associations decreased by $36-73 \%$ when they were indexed to BSA (Tab. 3). Similar observations were obtained both for the whole study group and separately for patients with $\mathrm{AF}$ and in the control group.

\section{Risk of AF occurrence associated with echocardiographic and nutritional parameters}

The lack of statistically significant relationships between parameters of adipose tissue distribution and the values of the echocardiographic parameters indexed to BSA might suggest that cardiac ultrasound morphology in our patients depended not on the patients' nutritional status, but on body size or individual, non-nutritional factors determining morphological and/or electrical cardiac remodelling. This hypothesis might run counter to, for example, evidenced data linking obesity with the risk of AF $[1,2]$. Therefore, we performed analysis 


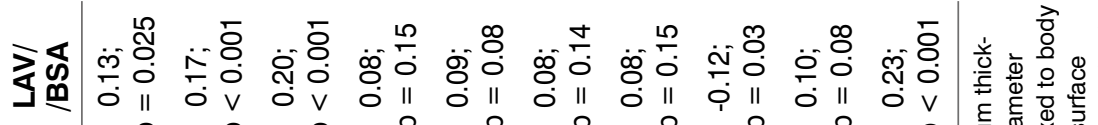

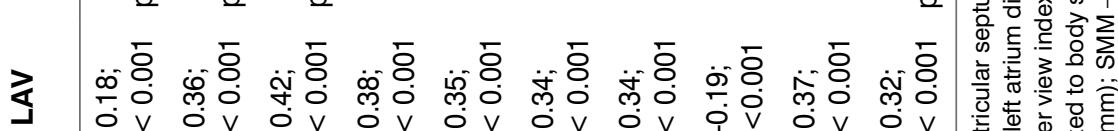

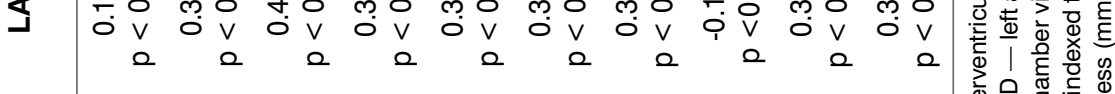

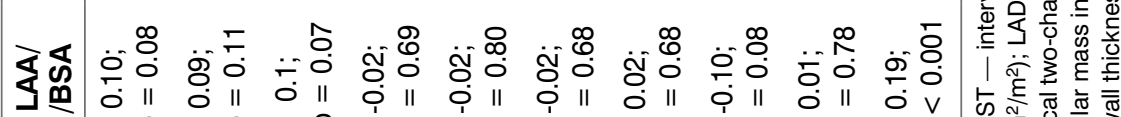

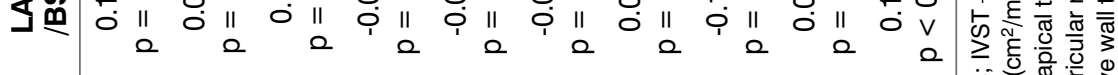

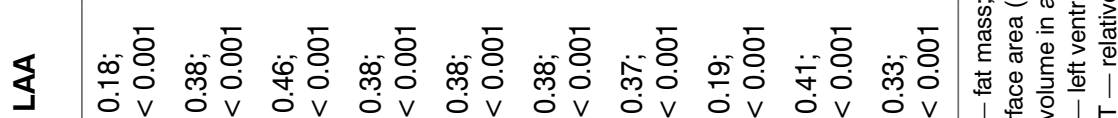

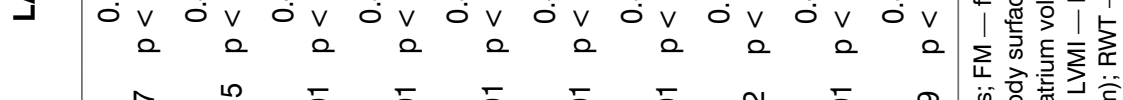

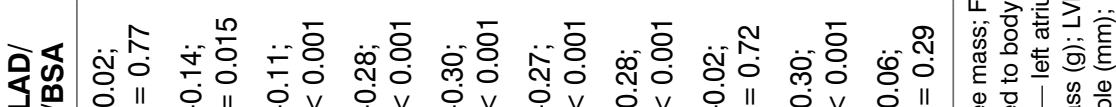

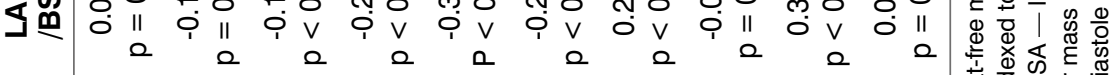

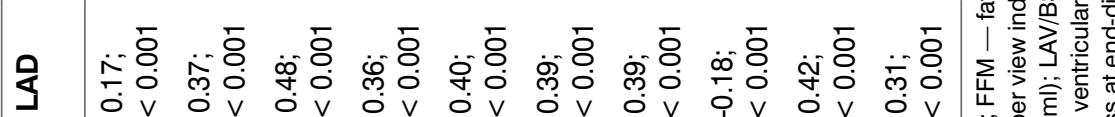

छे

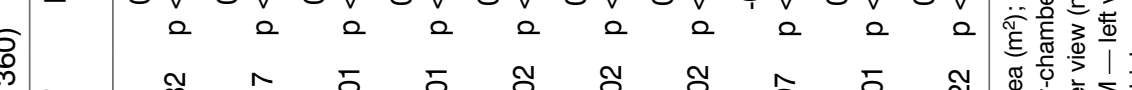

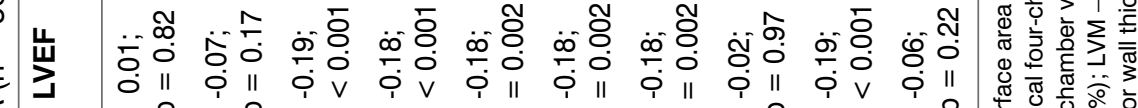

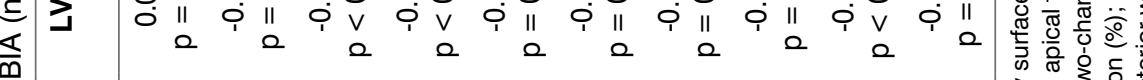

듀

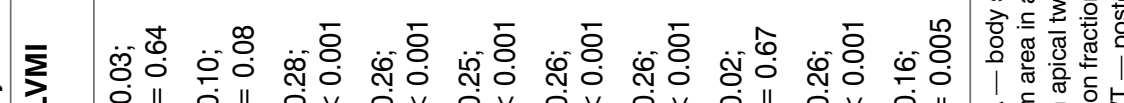

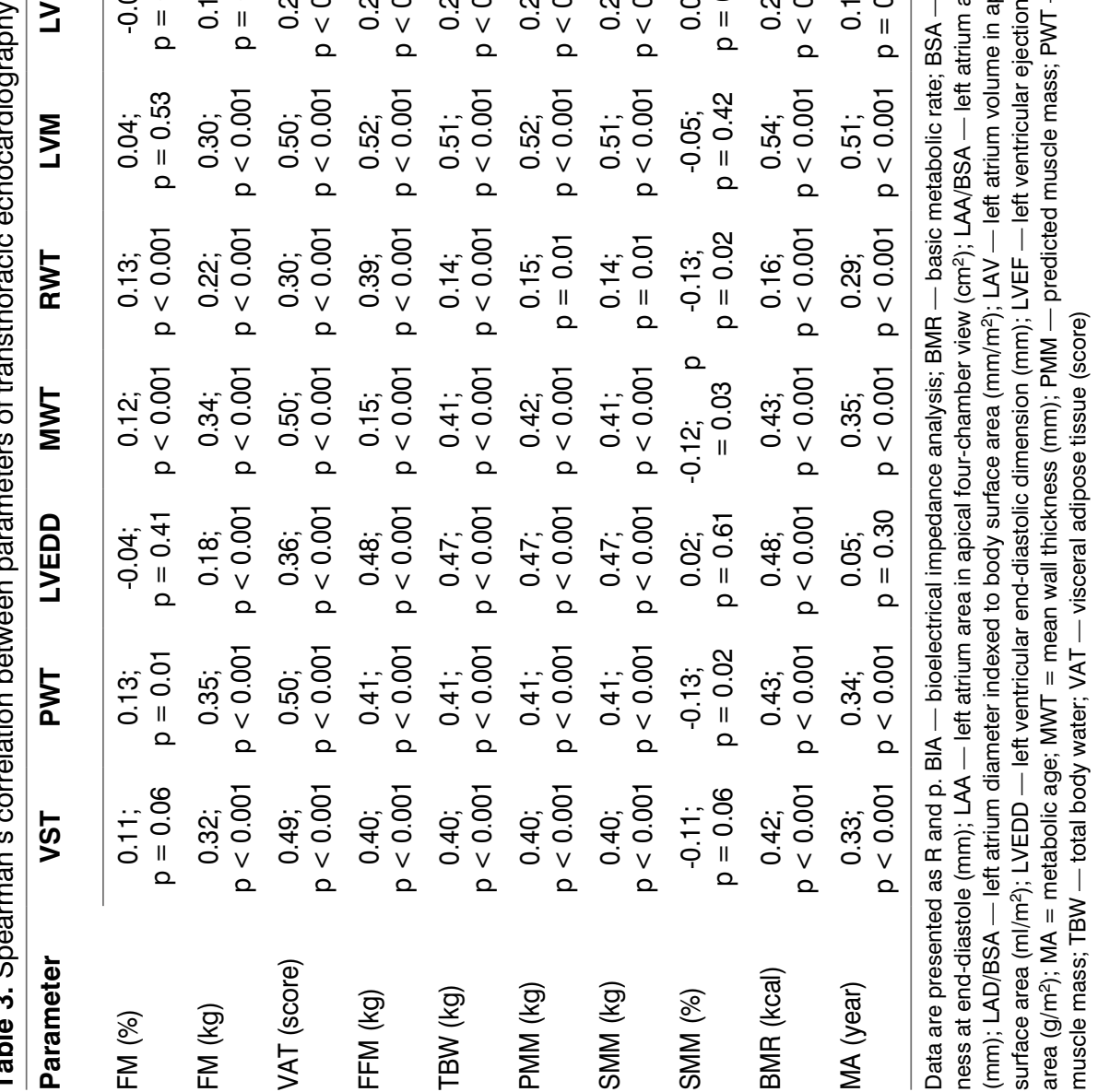


using logistic regression in order to determine the power of the relationships between nutritional status assessment and the values of the echocardiographic parameters and the risk of AF diagnosis (Tab. 4). When continuous values of respective parameters were taken into account in logistic regression analysis, it occurred that parameters of echocardiography (e.g. LVED, LAD, LAD/BSA, LAA4/BSA, and LAA2/BSA) are linked only slightly less or similar to the risk of AF [expressed as OR value] than the parameters of nutritional status assessment (Table 4). However, when OR values were calculated in relation to cut-off values obtained in ROC analysis, the significantly higher OR values referred to echocardiographic than nutritional parameters (Tab. 4). In other words, for example, the risk of AF was much considerably increased in patients with left atrium diameter $\geq 45 \mathrm{~mm}$ than those with obesity diagnosed on the base of the excess of FM found in BIA (FM>35\% for females and $>25 \%$ for males) and abdominal distribution of adipose tissue (e.g. VAT score $\geq 12$ ). Deficit of body mass did not significantly affect the risk of AF ([OR; 95\% Cl] 0.572; 0.250-1.305; $p=0.185$ ).

\section{Discussion}

In our study, we found relationships between parameters of body composition and echocardiographic parameters (Tab. 1-3). However, indexing heart ultrasound parameters to BSA made their associations with parameters of nutritional status weaker (Tab. 3 ). Indices of body composition analysis explained $2-27 \%$ of crude (unindexed) and $2-8 \%$ of the indexed echocardiographic parameter values (Tab. 3). We further found that parameters of obesity and abdominal adiposity compared to parameters of transthoracic echocardiography predicted AF risk similarly or only little weaker, however, only when they were taken into account as continuous variables (Tab. 4). However, when we calculated OR variables in relation to cut-off values obtained in ROC analysis, the prediction power for echocardiography was stronger than for parameters of nutritional status assessment.

The links between obesity and the risk of AF and other cardiovascular conditions found in our study have been evidenced previously $[1,2,17]$. The evidence for the associations mentioned is strengthened through a reported favorable effect of weight reduction on the risk of AF occurrence [8, 9]. However, the relationships between parameters of body composition in BIA and parameters of echocardiography and between echocardiographic parameters and undernutrition have only been explored in one publication apiece [5]. The results of these works corroborate ours (Tab. 1, 3, 4). In a study by Mancusi et al. [18], obesity was associated with a 6.9 times higher prevalence of LV hypertrophy. In research by Huang et al. [5], obese patients had larger $L A D$, LAA, and LAV, both in univariate and multivariate analysis. Dibeklioglu et al. [19] showed that obesity in children was a risk factor for LV hypertrophy independent of hypertension, and Kurisu et al. [20] found an influence of BMI on the correlations between LVM and ECG indices used in the diagnosis of LV hypertrophy, such as the Cornell product and Sokolow-Lyon indices.

Our results are also consistent with the outcome of investigations exploring the effect of visceral adipose tissue distribution on echocardiographic parameters and risk of AF (Tab. 2). Yoon et al. [21] reported a significant trend in increasing values of LVM/BSA and LAD across VAT tertiles. In a study by Chau et al. [22], individuals with elevated waist circumference had a twofold higher risk of diastolic dysfunction of LV than those without central adiposity. In an investigation by Tugcu et al. [23], higher WC was significantly associated with higher LAV. Using multivariable logistic regression models, Son et al. [24] also found significant relationships between WC and enlargement of LA and LV and LV hypertrophy in healthy male Koreans. Mornar Jelavić et al. [16] reported that among patients with acute ST-elevation myocardial infarction (STEMI) treated with the percutaneous coronary intervention ( $\mathrm{PCl})$, those with abdominal adiposity defined by greater WHR values had higher rates of significantly stenosed proximal/middle coronary segments, while those with a greater $\mathrm{WHtR}$ had the highest rates of heart failure and total in-hospital complications. Markus et al. [7] used multivariable-adjusted linear regression models to analyze the effect of changes in body composition measured using BIA during a 5 year period on changes in LV geometry and function. They found that a $1 \mathrm{~kg}$ increase/decrease in TBW or FM was associated, respectively, with an increase/decrease of $0.89 \mathrm{~g}$ or $1.84 \mathrm{~g}$ in LVM, and an increase in FM was associated with LV concentric remodelling and impairment of systolic and diastolic function parameters, whereas an increase in FFM was associated with LV eccentric remodelling and improved systolic and diastolic functional variables. Moreover, eker et al. [25] reported that epicardial adipose tissue thickness was independently associated with abnormal LV geometry, hypertrophy, and dysfunction, as well as low-grade chronic inflammation. A study by Bairapareddy et al. [26] showed that EAT correlated with VAT, so we can assume that results by Şeker et al. [25] indirectly corroborate our observations.

In our study, we also found that both general (higher FM expressed in $\mathrm{kg}$ ) and central (greater VAT score) adiposity were similar or only a little weaker indicators of the risk of AF occurrence as crude and indexed echocardiographic parameters (Tab. 4). Only the comparison of the predictive power of cut-off values established in ROC 
Table 4. Risk of atrial fibrillation occurrence associated with clinical, nutritional status and echocardiographic parameters among inpatients with cardiovascular disorders $(n=360)$

\begin{tabular}{|c|c|c|c|}
\hline $\begin{array}{l}\text { Clinical and } \\
\text { echocardiographic } \\
\text { parameter }\end{array}$ & OR; $95 \% \mathrm{Cl}$ & $\begin{array}{l}\text { Parameter of nutritional } \\
\text { status assessment }\end{array}$ & OR; $95 \% \mathrm{Cl}$ \\
\hline Diabetes mellitus & $0.779 ; 0.496-1.223$ & Age & $1.003 ; 0.980-1.027$ \\
\hline Hypertension & $0.760 ; 0.413-1.399$ & Gender & $0.968 ; 0.621-1.509$ \\
\hline LVEDD (per mm) & $1.062 ; 1.026-1.100$ & Weight (per $1 \mathrm{~kg} \mathrm{~kg}$ ) & $1.027 ; 1.014-1.041$ \\
\hline LVEDD ( $\geq 48$ mm) & $28.928 ; 3.938-212.490$ & Weight $\geq 90 \mathrm{~kg}$ & $3.081 ; 1.898-5.001$ \\
\hline $\operatorname{LVEF}(\%)$ & $0.945 ; 0.926-0.966$ & Height (per $1 \mathrm{~cm}$ ) & $1.011 ; 0.989-1.035$ \\
\hline LVED $\geq 50 \%$ & $0.361 ; 0.198-0.660$ & BMI (per $\left.1 \mathrm{~kg} / \mathrm{m}^{2}\right)$ & $1.087 ; 1.043-1.132$ \\
\hline IVST (per mm) & $1.157 ; 0.80-1.299$ & $\mathrm{BMl} \geq 30.27 \mathrm{~kg} / \mathrm{m}^{2}$ & $3.044 ; 1.913-4.843$ \\
\hline IVST ( $\geq 11 \mathrm{~mm})$ & $2.108 ; 1.321-3.363$ & Actual-to-ideal body mass ratio & $1.018 ; 1.009-1.027$ \\
\hline PWT per (mm) & $1.267 ; 1.120-1.432$ & Waist circumference (per cm) & $1.021 ; 1.004-1.037$ \\
\hline LVM (per g) & Overabundance of data & $W C \geq 108 \mathrm{~cm}$ & $2.391 ; 1.521-3.759$ \\
\hline LVM $(\geq 185.90 \mathrm{~g})$ & $3.006 ; 1.846-4.895$ & Triceps skinfold thickness (mm) & $1.021 ; 0.997-1.045$ \\
\hline LAD (per mm) & $1.190 ; 1.135-2.247$ & $\begin{array}{l}\text { Subscapular skinfold thickness } \\
\text { (per mm) }\end{array}$ & $1.005 ; 0.979-1.031$ \\
\hline $\mathrm{LAD} \geq 45 \mathrm{~mm}$ & $10.483 ; 6.308-17.421$ & $\begin{array}{l}\text { Abdominal (suprailiac) skinfold } \\
\text { thickness (per mm) }\end{array}$ & Overabundance of data \\
\hline LAA4 (per $\left.\mathrm{cm}^{2}\right)$ & $1.113 ; 1.065-1.162$ & WHR & $1.089 ; 0.573-2.071$ \\
\hline $\mathrm{LAA} 4 \geq 21.50 \mathrm{~cm}^{2}$ & $14.623 ; 8.089-26.437$ & WHR for abdominal adiposity & $1.24 ; 0.704-2.186$ \\
\hline LAA2 (per $\left.\mathrm{cm}^{2}\right)$ & $1.247 ; 1.181-1.316$ & $\mathrm{WHtR}$ & $1.029 ; 1.003-1.057$ \\
\hline LAA2 $\geq 23.90 \mathrm{~cm}^{2}$ & $9.405 ; 5.670-15.598$ & WHtR for abdominal adiposity & $1.519 ; 0.971-2.376$ \\
\hline LAV4 (per ml) & $1.039 ; 1.029-1.049$ & FM (per \% of body mass) & $1.056 ; 1.028-1.084$ \\
\hline LAV4 $\geq 69.50 \mathrm{ml}$ & $10.617 ; 5.661-19.913$ & Obesity (FM, \%) & $2.015 ; 1.231-3.298$ \\
\hline LAV2 (per ml) & $1.042 ; 1.032-1.053$ & $F M \geq 32.60 \%$ & $2.624 ; 1.606-4.289$ \\
\hline LAV2 $\geq 93.60 \mathrm{ml}$ & $10.271 ; 6.182-17.065$ & FM (per kg) & $1.062 ; 1.038-1.087$ \\
\hline LVM/BSA $\left(\mathrm{g} / \mathrm{m}^{2}\right)$ & $1.012 ; 1.005-1.020$ & $\mathrm{FM} \geq 26 \mathrm{~kg}$ & $4.095 ; 2.463-6.807$ \\
\hline LVM/BSA $\geq 102.77 \mathrm{~g} / \mathrm{m}^{2}$ & $2.304 ; 1.443-3.678$ & VAT (per 1 score) & $1.140 ; 1.086-1.218$ \\
\hline LAD/BSA $\left(\mathrm{mm} / \mathrm{m}^{2}\right)$ & $1.196 ; 1.115-1.283$ & VAT $\geq 12$ (score) & $3.091 ; 1.857-5.153$ \\
\hline $\mathrm{LAD} / \mathrm{BSA} \geq 23 \mathrm{~mm} / \mathrm{m}^{2}$ & $3.346 ; 2.120-5.279$ & FFM (per kg) & $1.023 ; 1.008-1.044$ \\
\hline LAA4/BSA (per $\left.\mathrm{cm}^{2} / \mathrm{m}^{2}\right)$ & $1.195 ; 1.104-1.294$ & $\mathrm{FFM} \geq 51.80 \mathrm{~kg}$ & $1.799 ; 1.109-2.916$ \\
\hline $\mathrm{LAA} 4 / \mathrm{BSA} \geq 11.78 \mathrm{~cm}^{2} / \mathrm{m}^{2}$ & $7.136 ; 4.368-11.660$ & PPM (per kg) & $1.024 ; 1.002-1.046$ \\
\hline LAA2/BSA $\left(\right.$ per $\left.\mathrm{cm}^{2} / \mathrm{m}^{2}\right)$ & $1.381 ; 1.255-1.519$ & $\mathrm{PPM} \geq 49.20 \mathrm{~kg}$ & $1.799 ; 1.109-2.916$ \\
\hline $\mathrm{LAA} 2 / \mathrm{BSA} \geq 6.78 \mathrm{~cm}^{2} / \mathrm{m}^{2}$ & $0.512 ; 0.03-8.27$ & SMM (per kg) & $1.041 ; 1.004-1.071$ \\
\hline LAV4/BSA (per $\mathrm{ml} / \mathrm{m}^{2}$ ) & $1.071 ; 1.051-1.092$ & $\mathrm{SMM} \geq 29.30 \mathrm{~kg}$ & $1.815 ; 1.120-2.941$ \\
\hline $\mathrm{LAV} 4 / \mathrm{BSA} \geq 39.03 \mathrm{ml} / \mathrm{m}^{2}$ & $6.182 ; 3.706-10.315$ & SMM (per $1 \%$ of body mass) & $0.907 ; 0.866-0.951$ \\
\hline LAV2/BSA (per ml/m²) & $1.077 ; 1.055-1.098$ & $\mathrm{SMM} \geq 52 \%$ & $1.050 ; 0.094-11.717$ \\
\hline $\mathrm{LAV} 2 / \mathrm{BSA} \geq 46.25 \mathrm{ml} / \mathrm{m}^{2}$ & $7.707 ; 4.722-12.582$ & & \\
\hline
\end{tabular}

Data are presented as odds ratio (OR) and 95 confidence interval $(95 \% \mathrm{Cl})$; ns - not significant. OR; $95 \% \mathrm{Cl}$ were calculated using logistic regression for quantitative variables, and using the proportional formula for qualitative variables. BMI — body mass index; BSA — body surface area; DM — diabetes mellitus; FFM — fat-free mass; FM — fat mass; IVST — interventricular septum thickness at end-diastole; LAA2 — left atrium area in apical two-chamber view; LAA2/BSA — left atrium area in apical two-chamber view indexed to body surface area; LAA4 — left atrium area in apical four-chamber view; LAA4/BSA — left atrium area in apical four-chamber view indexed to body surface area; LAD — left atrium diameter; LAD/BSA — left atrium diameter indexed to body surface area; LAV2 — left atrium volume in apical two-chamber view; LAV2/ BSA - left atrium volume in apical two-chamber view indexed to body surface area; LAV4 - left atrium volume in apical four-chamber view; LAV4/BSA — left atrium volume in apical four-chamber view indexed to body surface area; LVEDD — left ventricular end-diastolic dimension; LVEF — left ventricular ejection fraction; LVM — left ventricular mass; LVM/BSA — left ventricular mass indexed to body surface area; ns- nonsignificant statistically; PMM — predicted muscle mass; PWT — posterior wall thickness at end-diastole; RWT — relative wall thickness; SMM — skeletal muscle mass; VAT — visceral adipose tissue; WHR — waist-to-hip ratio; WHtR — waist-to-height ratio 
analysis showed that AF risk was associated significantly stronger with e.g. LVED $\geq 48 \mathrm{~mm}$, LAA $4 \geq 21,50 \mathrm{~cm}^{2}$ or $L A D \geq 45 \mathrm{~mm}$ than with $F M \geq 26 \mathrm{~kg}$, VAT score $\geq 12$, body weight $\geq 90 \mathrm{~kg}$, and $\mathrm{BMI} \geq 30.27 \mathrm{~kg} / \mathrm{m}^{2}$. The associations between values of echocardiographic parameters and the risk of AF, the outcome of AF treatment and patients prognosis are well known, both in relation to the left atrium and left ventricle echocardiographic parameters [27]. Huang et al. [5] found that a higher risk of AF was independently associated with greater LAD and older age, but not with BMI and gender. In contrast, Winkle et al. [28] reported worse AF ablation outcomes among patients with a $\mathrm{BMI} \geq 35 \mathrm{~kg} / \mathrm{m}^{2}$. Moreover, patients undergoing AF ablation who had a BMI $\geq 40 \mathrm{~kg} / \mathrm{m}^{2}$ had a higher risk of minor complications. These last observations may be explained by the above-mentioned data concerning the effect of adiposity (FM, VAT and EAT) on heart remodelling $[7,25]$. The influence is related to a direct paracrine effect of EAT, the thickness of which correlates with visceral adiposity, as well as the endocrine and proinflammatory activity of VAT $[10-12,26]$.

The results of this study have some limitations. Firstly, our study group consisted of inpatients from one medical center and was relatively small. Secondly, our study had a cross-sectional design, so we were unable to observe AF occurrence over a long period of time among patients whose body composition had been determined previously.

\section{Conclusions}

The values of echocardiographic parameters are only slightly associated with patients' nutritional status and abdominal adiposity and these relationships become weaker after adjustment for body surface area. The risk of AF occurrence was slightly more strongly or equally predicted using unitary values of echocardiographic parameters than through parameters of body composition, however, the use of cut-off values for echocardiographic parameters importantly increased their predictive power in comparison to parameters of abdominal adiposity.

\section{Acknowledgement: This study was supported} by the grant of Nicolaus Copernicus University for statutory activity of Department of Vascular and Internal Diseases.

\section{Conflict of interest: None declared.}

\section{References}

1. Anaszewicz M, Budzyński J. Clinical significance of nutritional status in patients with atrial fibrillation: An overview of current evidence. J Cardiol. 2017; 69(5): 719-730, doi: 10.1016/j.jjcc.2016.06.014, indexed in Pubmed: 27520756.
2. Budzyński J, Anaszewicz M. The associations between atrial fibrillation and parameters of nutritional status assessment in the general hospital population - a cross-sectional analysis of medical documentation. Kardiol Pol. 2017; 75(3): 231-239, doi: 10.5603/KP.a2016.0182, indexed in Pubmed: 27995601.

3. Pathak RK, Middeldorp ME, Lau DH, et al. Aggressive risk factor reduction study for atrial fibrillation and implications for the outcome of ablation: the ARREST-AF cohort study. J Am Coll Cardiol. 2014; 64(21): 2222-2231, doi: 10.1016/j.jacc.2014.09.028, indexed in Pubmed: 25456757.

4. Pathak RK, Elliott A, Middeldorp ME, et al. Impact of CARDIOrespiratory FITness on Arrhythmia Recurrence in Obese Individuals With Atrial Fibrillation: The CARDIO-FIT Study. J Am Coll Cardiol. 2015; 66(9): 985-996, doi: 10.1016/j.jacc.2015.06.488, indexed in Pubmed: 26113406

5. Huang G, Parikh PB, Malhotra A, et al. Relation of Body Mass Index and Gender to Left Atrial Size and Atrial Fibrillation. Am J Cardio 2017; 120(2): 218-222, doi: 10.1016/..amjcard.2017.04.013, indexed in Pubmed: 28583686

6. Bello NA, Cheng S, Claggett B, et al. Association of Weight and Body Composition on Cardiac Structure and Function in the ARIC Study (Atherosclerosis Risk in Communities). Circ Heart Fail. 2016; 9(8) doi: 10.1161/CIRCHEARTFAILURE.115.002978, indexed in Pubmed: 27512104

7. Markus MR, Werner N, Schipf S, et al. Changes in Body Weight and Composition Are Associated With Changes in Left Ventricular Geometry and Function in the General Population: SHIP (Study of Health in Pomerania). Circ Cardiovasc Imaging. 2017; 10(3): e005544, doi 10.1161/CIRCIMAGING.116.005544, indexed in Pubmed: 28298284.

8. Lee SC, Daimon M, Di Tullio MR, et al. Beneficial effect of body weight control on left ventricular diastolic function in the general population: an analysis of longitudinal data from a health check-up clinic. Eur Heart J Cardiovasc Imaging. 2018; 19(2): 136-142, doi: 10.1093/ehjci/jex219, indexed in Pubmed: 29237001.

9. Le Jemtel TH, Samson R, Jaiswal A, et al. Regression of Left Ventricular Mass After Bariatric Surgery. Curr Hypertens Rep. 2017; 19(9): 68, doi: 10.1007/s11906-017-0767-5, indexed in Pubmed: 28755274.

10. Psychari SN, Tsoukalas D, Varvarousis D, et al. Opposite relations of epicardial adipose tissue to left atrial size in paroxysmal and permanent atrial fibrillation. SAGE Open Med. 2018; 6: 2050312118799908, doi: 10.1177/2050312118799908, indexed in Pubmed: 30245816.

11. von Jeinsen B, Short MI, Xanthakis V, et al. Association of Circulating Adipokines With Echocardiographic Measures of Cardiac Structure and Function in a Community-Based Cohort. J Am Heart Assoc. 2018. 7(13), doi: 10.1161/JAHA.118.008997, indexed in Pubmed: 29929991.

12. Cescau A, Van Aelst LNL, Baudet M, et al. High body mass index is a predictor of left ventricular reverse remodelling in heart failure with reduced ejection fraction. ESC Heart Fail. 2017; 4(4): 686-689, doi 10.1002/ehf2.12172, indexed in Pubmed: 28752617

13. Zhang $C$, Deng $Y$, Liu $Y$, et al. Preclinical cardiovascular changes in children with obesity: A real-time 3-dimensional speckle tracking imaging study. PLoS One. 2018; 13(10): e0205177, doi: 10.1371/journal. pone.0205177, indexed in Pubmed: 30308043

14. Ashwell M Gunn P Gibson S. Waist-to-height ratio is a better screening tool than waist circumference and BMI for adult cardiometabolic risk factors: systematic review and meta-analysis. Obes Rev. 2012 13(3): 275-286, doi: 10.1111/j.1467-789X.2011.00952.x, indexed in Pubmed: 22106927

15. Shen S, Lu Y, Qi H, et al. Waist-to-height ratio is an effective indicator for comprehensive cardiovascular health. Sci Rep. 2017; 7: 43046, doi: 10.1038/srep43046, indexed in Pubmed: 28220844.

16. Mornar Jelavić M, Babić Z, Pintarić $\mathrm{H}$, et al. The Role of Anthropometry in Acute St-Elevation Myocardial Infarction Treated with Primary Percutaneous Coronary Intervention. Acta Clin Croat. 2016; 55(2): 224-232, doi: 10.20471/acc.2016.55.02.07, indexed in Pubmed: 28394109.

17. Piepoli MF, Hoes AW, Agewall S, et al. Authors/Task Force Members:, Authors/Task Force Members, Additional Contributor: Simone Binno (Italy), Document Reviewers:, ESC Scientific Document Group. 2016 European Guidelines on cardiovascular disease prevention in clinical practice: The Sixth Joint Task Force of the European Society of Cardiology and Other Societies on Cardiovascular Disease Prevention in Clinical Practice (constituted by representatives of 10 societies and by invited experts)Developed with the special contribution of the European Association for Cardiovascular Prevention \& Rehabilitation (EACPR). Eur Heart J. 2016; 37(29): 2315-2381, doi: 10.1093/eurheartj/ehw106, indexed in Pubmed: 27222591.

18. Mancusi C, Gerdts E, Losi MA, et al. Differential effect of obesity on prevalence of cardiac and carotid target organ damage in hypertension (the Campania Salute Network). Int J Cardiol. 2017; 244: 260-264, doi: 10.1016/j.ijcard.2017.06.045, indexed in Pubmed: 28629621 
19. Dibeklioglu SE, Cevik BS, Acar B, et al. The association between obesity, hypertension and left ventricular mass in adolescents. Pediatr Endocrinol Metab. 2017; 30(2): 167-174, doi: 10.1515/jpem2016-0170, indexed in Pubmed: 28099129.

20. Kurisu S, Ikenaga H, Watanabe N, et al. Implications of World Health Organization classification for body mass index on the correlations between common electrocardiographic indexes for left ventricular hypertrophy and left ventricular mass. Clin Exp Hypertens. 2016 38(8): 715-720, doi: 10.1080/10641963.2016.1200604, indexed in Pubmed: 27936957.

21. Yoon HE, Choi SSu, Kim Y, et al. The Clinical Usefulness of Measurement of Visceral Fat Area Using Multi-Frequency Bioimpedance: The Association with Cardiac and Renal Function In General Population with Relatively Normal Renal Function. Int J Med Sci. 2017; 14(13) 1375-1381, doi: 10.7150/ijms.21393, indexed in Pubmed: 29200951

22. Chau K, Girerd N, Magnusson M, et al. Obesity and metabolic features associated with long-term developing diastolic dysfunction in an initially healthy population-based cohort. Clin Res Cardiol. 2018 107(10): 887-896, doi: 10.1007/s00392-018-1259-6, indexed in Pubmed: 29680861

23. Tugcu A, Russo C, Jin Z, et al. Association of body size metrics with left atrial phasic volumes and reservoir function in the elderly. Eur Heart
J Cardiovasc Imaging. 2018; 19(10): 1157-1164, doi: 10.1093/ehjci/jex236, indexed in Pubmed: 29059376.

24. Son JW, Sung JK, Lee JW, et al. Abdominal obesity and structure and function of the heart in healthy male Koreans: The ARIRANG study. Medicine (Baltimore). 2016; 95(39): e4930, doi: 10.1097/MD.0000000000004930, indexed in Pubmed: 27684832

25. Seker T, Türkoğlu C, Harbalıoğlu H, et al. Epicardial Fat Thickness is Associated with Abnormal Left Ventricle Geometry in Newly Diagnosed Hypertension. Acta Cardiol Sin. 2018; 34(3): 280-287, doi: 10.6515/ACS.201805 34(3).20171209A, indexed in Pubmed: 29844650.

26. Bairapareddy KC, Maiya AG, Kumar P, et al. Effect of aerobic exercise on echocardiographic epicardial adipose tissue thickness in overweight individuals. Diabetes Metab Syndr Obes. 2018; 11: 303-312, doi: 10.2147/DMSO.S145862, indexed in Pubmed: 29950876

27. Kirchhof P, Benussi S, Kotecha D, et al. ESC Scientific Document Group. 2016 ESC Guidelines for the management of atrial fibrillation developed in collaboration with EACTS. Eur Heart J. 2016; 37(38): 2893-2962, doi: 10.1093/eurhearti/ehw210, indexed in Pubmed: 27567408.

28. Winkle RA, Mead RH, Engel G, et al. Impact of obesity on atrial fibrillation ablation: Patient characteristics, long-term outcomes, and complications. Heart Rhythm. 2017; 14(6): 819-827, doi: 10.1016/j. hrthm.2017.02.023, indexed in Pubmed: 28232261. 